NASA/TM-2006-214224

\title{
Performance Assessment of a Large Scale Pulsejet- Driven Ejector System
}

Daniel E. Paxson

Glenn Research Center, Cleveland, Ohio

Paul J. Litke and Frederick R. Schauer

Air Force Research Laboratory

Wright-Patterson Air Force Base

Dayton, Ohio

Royce P. Bradley and John L. Hoke

Innovative Scientific Solutions, Inc.

Dayton, Ohio 


\section{NASA STI Program . . . in Profile}

Since its founding, NASA has been dedicated to the advancement of aeronautics and space science. The NASA Scientific and Technical Information (STI) program plays a key part in helping NASA maintain this important role.

The NASA STI Program operates under the auspices of the Agency Chief Information Officer. It collects, organizes, provides for archiving, and disseminates NASA's STI. The NASA STI program provides access to the NASA Aeronautics and Space Database and its public interface, the NASA Technical Reports Server, thus providing one of the largest collections of aeronautical and space science STI in the world. Results are published in both non-NASA channels and by NASA in the NASA STI Report Series, which includes the following report types:

- TECHNICAL PUBLICATION. Reports of completed research or a major significant phase of research that present the results of NASA programs and include extensive data or theoretical analysis. Includes compilations of significant scientific and technical data and information deemed to be of continuing reference value. NASA counterpart of peer-reviewed formal professional papers but has less stringent limitations on manuscript length and extent of graphic presentations.

- TECHNICAL MEMORANDUM. Scientific and technical findings that are preliminary or of specialized interest, e.g., quick release reports, working papers, and bibliographies that contain minimal annotation. Does not contain extensive analysis.

- CONTRACTOR REPORT. Scientific and technical findings by NASA-sponsored contractors and grantees.
- CONFERENCE PUBLICATION. Collected papers from scientific and technical conferences, symposia, seminars, or other meetings sponsored or cosponsored by NASA.

- SPECIAL PUBLICATION. Scientific, technical, or historical information from NASA programs, projects, and missions, often concerned with subjects having substantial public interest.

- TECHNICAL TRANSLATION. Englishlanguage translations of foreign scientific and technical material pertinent to NASA's mission.

Specialized services also include creating custom thesauri, building customized databases, organizing and publishing research results.

For more information about the NASA STI program, see the following:

- Access the NASA STI program home page at http://www.sti.nasa.gov

- E-mail your question via the Internet to help@sti.nasa.gov

- Fax your question to the NASA STI Help Desk at 301-621-0134

- Telephone the NASA STI Help Desk at 301-621-0390

- Write to:

NASA STI Help Desk

NASA Center for AeroSpace Information 7121 Standard Drive Hanover, MD 21076-1320 
NASA/TM-2006-214224

AIAA-2006-1021

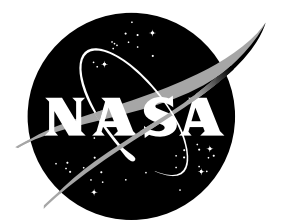

\section{Performance Assessment of a Large Scale Pulsejet- Driven Ejector System}

\section{Daniel E. Paxson}

Glenn Research Center, Cleveland, Ohio

Paul J. Litke and Frederick R. Schauer

Air Force Research Laboratory

Wright-Patterson Air Force Base

Dayton, Ohio

Royce P. Bradley and John L. Hoke

Innovative Scientific Solutions, Inc.

Dayton, Ohio

Prepared for the

44th Aerospace Sciences Meeting and Exhibit

sponsored by the American Institute of Aeronautics and Astronautics

Reno, Nevada, January 9-12, 2006

National Aeronautics and

Space Administration

Glenn Research Center

Cleveland, Ohio 44135 
This report is a formal draft or working paper, intended to solicit comments and ideas from a technical peer group.

This report contains preliminary findings, subject to revision as analysis proceeds.

This work was sponsored by the Fundamental Aeronautics Program at the NASA Glenn Research Center.

Level of Review: This material has been technically reviewed by technical management.

Available from

NASA Center for Aerospace Information 7121 Standard Drive

Hanover, MD 21076-1320
National Technical Information Service 5285 Port Royal Road Springfield, VA 22161 


\title{
Performance Assessment of a Large Scale Pulsejet- Driven Ejector System
}

\author{
Daniel E. Paxson \\ National Aeronautics and Space Administration \\ Glenn Research Center \\ Cleveland, Ohio 44135 \\ Paul J. Litke and Frederick R. Schauer \\ Air Force Research Laboratory \\ Wright-Patterson Air Force Base \\ Dayton, Ohio 45433 \\ Royce P. Bradley and John L. Hoke \\ Innovative Scientific Solutions, Inc. \\ Dayton, Ohio 45440
}

\begin{abstract}
Unsteady thrust augmentation was measured on a large scale driver/ejector system. A 72 in. long, 6.5 in. diameter, $100 \mathrm{lb}_{\mathrm{f}}$ pulsejet was tested with a series of straight, cylindrical ejectors of varying length, and diameter. A tapered ejector configuration of varying length was also tested. The objectives of the testing were to determine the dimensions of the ejectors which maximize thrust augmentation, and to compare the dimensions and augmentation levels so obtained with those of other, similarly maximized, but smaller scale systems on which much of the recent unsteady ejector thrust augmentation studies have been performed. An augmentation level of 1.71 was achieved with the cylindrical ejector configuration and 1.81 with the tapered ejector configuration. These levels are consistent with, but slightly lower than the highest levels achieved with the smaller systems. The ejector diameter yielding maximum augmentation was 2.46 times the diameter of the pulsejet. This ratio closely matches those of the small scale experiments. For the straight ejector, the length yielding maximum augmentation was 10 times the diameter of the pulsejet. This was also nearly the same as the small scale experiments. Testing procedures are described, as are the parametric variations in ejector geometry. Results are discussed in terms of their implications for general scaling of pulsed thrust ejector systems.
\end{abstract}

\section{Introduction}

In recent years there has been renewed interest in the concept of ejectors or thrust augmentors driven by unsteady propulsion devices. The reason for this stems primarily from the interest in Pulse Detonation Engine (PDE) based propulsion systems, which are decidedly unsteady, and which therefore seem natural candidates on which to use an ejector. It has been suggested in the past (ref. 1), and shown convincingly in numerous recent experiments (refs. 2 through 9) that under the proper operating conditions, and with a well designed ejector, thrust augmentation levels approaching or even exceeding 2.0 can be achieved with unsteady thrust sources as drivers. Thrust augmentation, $\phi$ is defined as the total time-averaged thrust provided by the ejector and driver system, $\bar{F}_{\text {total }}$ divided by the thrust of the driver alone, $\bar{F}_{\text {driver }}$.

$$
\phi=\frac{\bar{F}_{\text {total }}}{\bar{F}_{\text {driver }}}
$$

It has further been shown that these high levels can be reached using remarkably small ejectors in comparison to their steady state counterparts. Several studies have been conducted using actual PDE's as drivers (refs. 5, 7, and 9); however a number have used alternative unsteady thrust sources including simple pulsed valves (refs. 2 and 8 ), Hartmann-Sprenger resonance tubes (ref. 4), synthetic jets (ref. 6), and pulsejets (ref. 3). The results from each of 
these varied experiments have helped identify the factors which contribute to the superiority of unsteady ejector systems in general (and therefore how they can be optimized), and which factors are unique to the particular driver. For example, it is now generally agreed that the frequency, unsteadiness level (the standard deviation of the exhaust velocity for example), and exhaust gas temperature of the thrust source play a significant role in the maximum thrust augmentation that can be achieved (ref. 6). These and other parameters (ref. 10) characterize the emitted vortex associated with each pulse of any unsteady thrust device. This vortex plays a critical role in determining thrust augmentation, though the physical mechanism is not understood. It has been shown through experimental measurements for example that vortex diameter is closely matched to the diameter of the ejector yielding maximum thrust augmentation (refs. 5, 6, 10, and 11). On the other hand, it is believed that the strong emitted shock, uniquely associated with the PDE pulse, has a large, though currently not well understood, influence on the maximum attainable thrust augmentation.

Despite the many unsteady ejector experiments performed to date, and the growing body of understanding associated with them, generalization of some results is not yet possible because the experiments have shared a common scale, which is to say, small. The thrust levels have been low (less than $15 \mathrm{lb}_{\mathrm{f}}$ ), and the driver diameters have been between 1 and 2 in. Rules have been suggested relating the optimal diameter of the ejector as a fixed ratio relative to that of the driver; however, they are not definitive because all the drivers tested are nearly the same size. The experiment described in this paper was developed to at least partially address this issue.

A large pulsejet, approximately an order of magnitude larger in exhaust cross-sectional area and thrust than most recent tests, was operated with a series of ejectors of varying diameter, length, and shape (cylindrical and tapered). The geometric ejector parameters, along with the spacing between the pulsejet tailpipe and ejector inlet were systematically varied in order to determine the configuration yielding the highest thrust augmentation, as measured by the thrust stand to which the system was mounted. The results were then compared to previous experiments both in terms of augmentation achieved, and in terms of optimized ejector dimensions. This paper will describe the experiment including the major components (pulsejet, ejector sets, and thrust stand), construction, testing procedures, and parametric variations of ejector dimensions. Results will then be presented, and a discussion of findings will follow.

\section{Experimental Setup}

The experimental setup is shown in figure 1 with the major components labeled. These are the ejector ( 1 of 4 tested), the pulsejet, and the thrust stand. Each will be described.

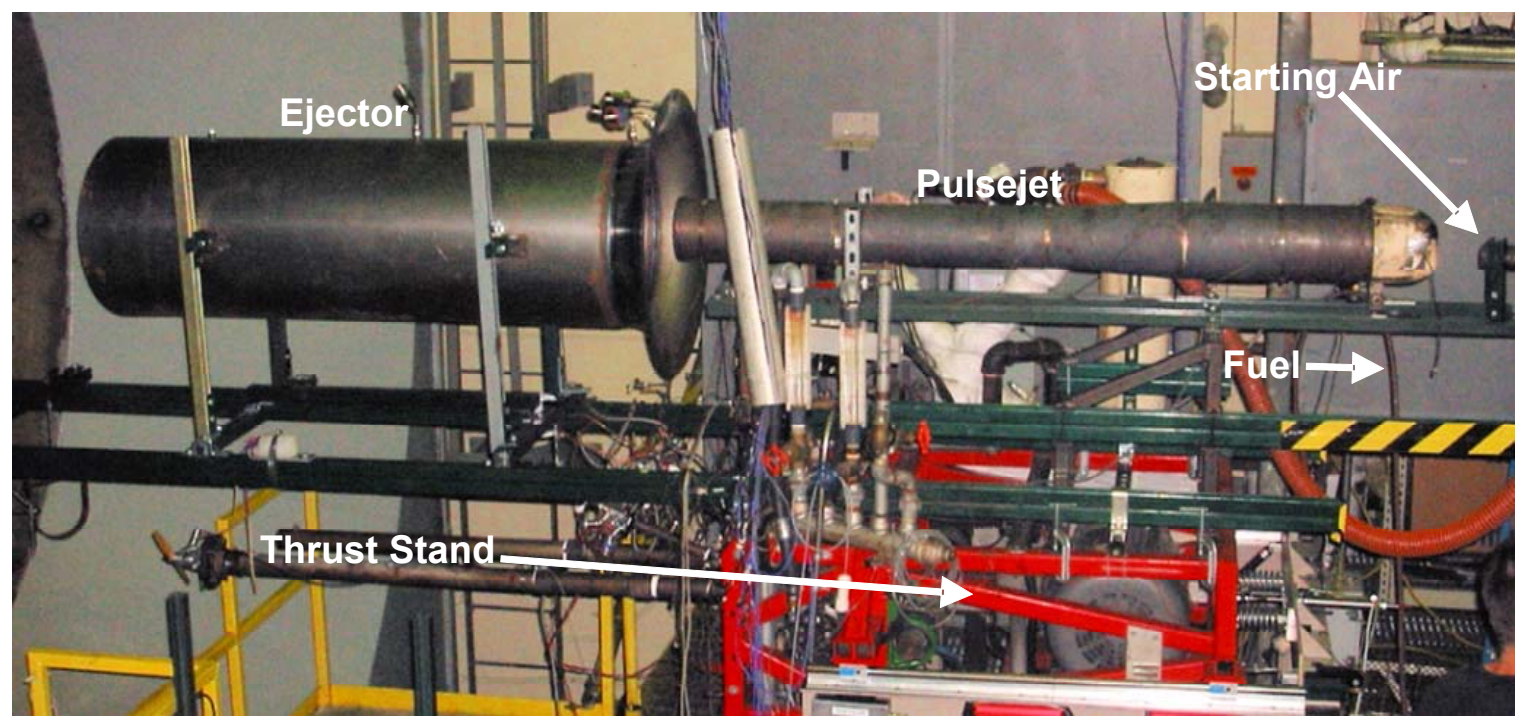

Figure 1.-Experimental setup. 


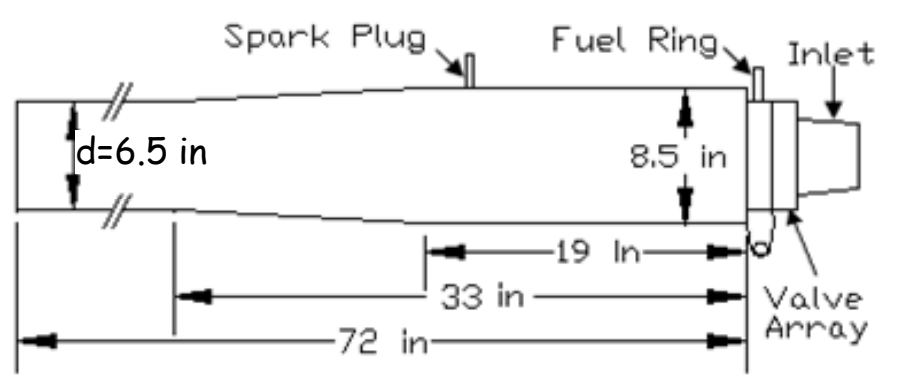

Figure 2.-Pulsejet schematic.

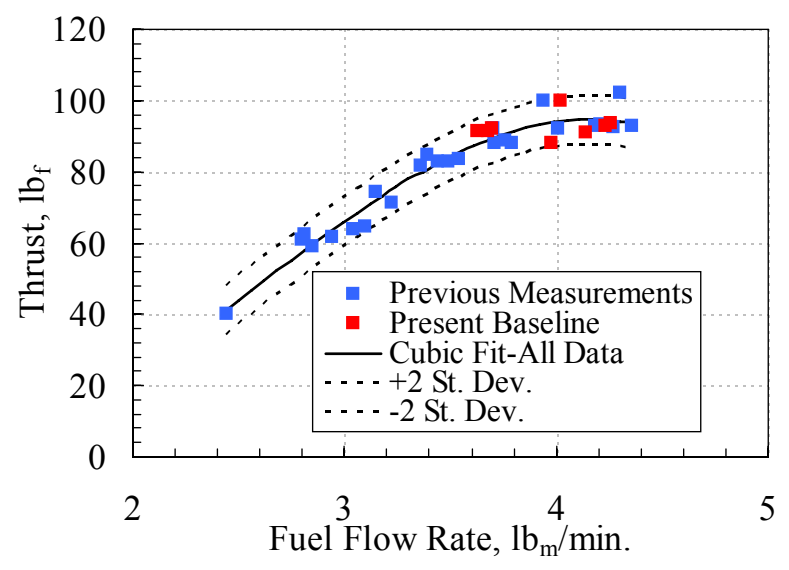

Figure 3.-Pulsejet thrust as a function of fuel flow.

\section{A. Pulsejet Driver}

The pulsejet tested and discussed in this paper is a Solar PJ32, originally developed and manufactured by the Solar Aircraft Company for the Globe Corporation Aircraft Division in 1951. Details of the device and performance characteristics are described in reference 13. Relevant dimensions are shown in the schematic of figure 2 . In brief, it is a self-aspirating, valved, unit which operates on liquid fuel (Avgas in this experiment) that is fed directly into the combustion chamber via a pressurized fuel line. Like most pulsejets it requires forced air directed at the inlet and a high frequency sparking system in the combustion chamber in order to initiate operation. However, once operation has commenced, the resonant nature of the device does not require forced air or spark. The fact that that fuel supply is pressurized (as opposed to a venturi-based arrangement found in small scale units (ref. 3) allows the pulsejet to be throttled in a reasonably predictable fashion. Figure 3 shows the relationship between measured thrust and fuel flow rate. Fuel flow rate is measured using an in-line turbine-type flow meter. Data is shown both from previous testing done to characterize the pulsejet (ref. 13), and from baseline testing done in the present experiment without an ejector installed. Also shown are a cubic fit to the data, and the bounds representing two standard deviations above and below the fit. It can be seen that a certain amount of scatter is present, which appears to be typical for pulsejets. For the present experiment, the pulsejet was operated near the maximum thrust point during all testing. The scatter in this operating region results in a maximum uncertainty of \pm 7 percent. For the present baseline data shown, the root-mean-square error between measured and curve-fit thrust was 3.7 percent. The maximum error was 6 percent.

The thrust stand can only measure total system thrust (pulsejet and ejector combined); however, thrust augmentation can only be determined if the thrust of the jet alone is known. One way to determine this is to simply run the pulsejet on the thrust stand without an ejector and use that thrust value as the baseline for all subsequent ejector tests. However, it is prohibitively time consuming to do this for each of the many ejector configurations tested. Instead, this measurement was made on average of once every sixteen operational runs of the engine. This method of determining jet-alone thrust will be referred to as Method I in subsequent sections of the paper where results are presented. If the rate of fuel flow could be accurately controlled, this method would suffice, save for the run-to-run uncertainty already described. The fuel flow rate through the system varied over time however, possibly due to clogging at the injectors. As a result, the same pressure in the fuel system did not always yield precisely the same flow rate. To account for this, the jet-alone thrust was also determined using the curve-fit presented above and 
the measured fuel flow rate from each run. This estimation method, referred to later as Method II, could be made each run, with or without an ejector present.

The frequency of operation of this pulsejet was $69 \mathrm{~Hz}$, with a standard deviation of $2 \mathrm{~Hz}$ for all of the testing performed. The operational frequency is weakly, and inversely related to the fuel flow rate. The observed frequency of the present tests was, like the thrust values, consistent with that observed in previous tests. It is interesting to note in passing that the product of operational frequency and length on this pulsejet is 15 percent higher than that for the small scale unit used in reference 3. Pulsejets are often thought of as gasdynamic devices with a frequency that is determined by the end-to-end transit time of a fixed set of dominant waves. All other things being equal, this conception implies that the product of frequency and length should be a constant. The observed difference therefore either indicates that the average temperature of the combustion products is 30 percent higher in the large unit (which would probably melt the steel), or that there are other elements contributing to the resonance than simply wave reflections (e.g., Helmholtz-like behavior, heat release rate, etc.).

\section{B. Ejectors}

Four ejectors were constructed from mild-steel sheet ranging in gage from 18 to 20. Scaled drawings of each are shown in figure 4, which also shows symbolic nomenclature for the relevant dimensions. Those dimensions are listed in table 1 . The commercially available bellmouth inlets were seamless, and terminated with a $1.0 \mathrm{in}$. long straight section. The main body of each cylindrical ejector was composed of a single rolled piece with a welded seam along the length. It was joined to the bellmouth with a circumferential weld. The main body of the tapered ejector was composed of two symmetric halves. The conical shape was achieved through a process called "bumping" whereby a small bend is applied approximately every inch along the circumference. This actually creates a many-sided polygon rather than a pure circular cross-section. The two halves were welded together along the entire length. The finished body was then attached to the inlet with a circumferential weld.

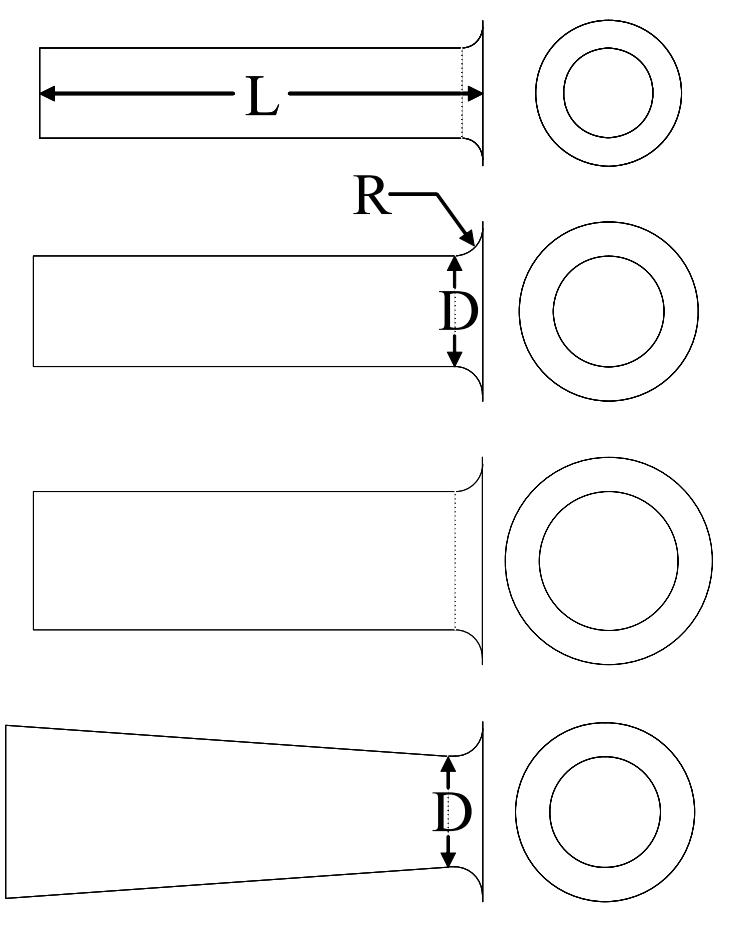

Figure 4.-Ejector schematics and symbols for relevant dimensions. 


\begin{tabular}{|c|c|c|}
\hline TABLE 1.-EJECTOR DIMENSIONS (AS-BUILT) \\
\hline $\begin{array}{c}R \\
\text { (in.) }\end{array}$ & $\begin{array}{c}L \\
\text { (in.) }\end{array}$ & $\begin{array}{c}D \\
\text { (in.) }\end{array}$ \\
\hline \multicolumn{3}{|c|}{ Straight, cylindrical } \\
\hline 3 & 64 & 13 \\
\hline 4 & 65 & 16 \\
\hline 4 & 65 & 20 \\
\hline 4 & 69 & 16 \\
\hline
\end{tabular}

The dimensions of the ejectors were chosen by a geometrical scaling of the small scale ejectors tested in the pulsejet-based experiments of reference 3. The length and diameter of the reference 3 ejector yielding the highest thrust augmentation was normalized by the diameter of the pulsejet driver (1.25 in.). Those ratios were then multiplied by the pulsejet diameter in the present work $(6.5 \mathrm{in}$.) to obtain the length and diameter of the central ejector. The other two diameters were then selected as 20 percent smaller and 25 percent larger than the central value with the supposition that this span would be sufficient to bound the value of the optimal diameter. The inlet radius, $R$ was not variable because the bellmouth inlets were commercially available stock-items, and the radius was pre-determined based on the selected diameter, $D$. However, it has been shown that while inlet rounding is necessary (a sharp-edged inlet will produced almost no augmentation), rounding beyond values of $R / D=0.15$ shows little benefit. The ejectors used in this experiment had $R / D \geq 0.20$.

\section{Thrust Stand}

Details of the thrust stand have been presented elsewhere in the literature (ref. 9 and 14). As such only a brief description will be given here. It consists of a cart with linear bearings which ride along a pair of fixed, low-friction rails. The test article (pulsejet or pulsejet and ejector combination) is rigidly attached to the cart. The cart pushes against a damped, calibrated spring, one end of which is fixed. Thrust is ultimately determined by measuring the cart displacement with a positional sensor which is low-pass filtered with a cut-off frequency of $0.5 \mathrm{~Hz}$. A time trace of measured thrust during a typical test run is shown in figure 5. The damping and filtering system is evidently quite effective, as there are no oscillations in the measured thrust. It is noted that there is a small positive thrust measured prior to engine ignition. This is the result of a preload applied to the spring at the zero point of the positional sensor.

\section{Test Procedure}

Each test run was approximately $30 \mathrm{sec}$ in duration and consisted of the following sequence. Fuel pressure was set. Starting air was then turned on as was the spark. Shortly thereafter the fuel flow valve was opened, and engine operation commenced. The starting air and spark were then shut off. After approximately $15 \mathrm{sec}$, the thrust reading would level off and for the next $15 \mathrm{sec}$ thrust was measured at approximately $1.0 \mathrm{sec}$ intervals. After the thrust measurement was acquired the fuel valve was closed, and the starting air was re-activated in order to provide cooling. The thrust data to be presented represents a simple time-average over the $15 \mathrm{sec}$ sampling period. This basic sequence is illustrated in figure 5 which shows actual test data from a typical run.

For each ejector tested, the baseline thrust of the pulsejet was first measured without the ejector present. A straight-sided ejector was then mounted on the thrust stand, with its axis of symmetry aligned with that of the pulsejet. Thrust measurements were made with the ejector inlet placed at various axial positions relative to the exhaust plane, as shown in figure 6. For each ejector, an optimal spacing value was found which yielded the highest thrust augmentation. This procedure was followed for each of the three straight ejector diameters.

The diameter yielding the highest thrust augmentation was then selected for length variation testing. It was first lengthened by welding a 19.5 in. extension to the cylindrical section, at the exhaust end. This modified ejector was then tested according to the procedure just described. The length of the ejector was then reduced by simply cutting off a portion of the exhaust end. The length reduction was done in increments of one pulsejet diameter (6.5 in.).

Due to resource limitations, it was possible to test only one tapered ejector. The minimum diameter of this ejector was chosen to be the same as that of the cylindrical ejector yielding the highest thrust augmentation. A tapered ejector made the same way was tested on several small scale rigs and found to yield very high thrust augmentation levels (refs. 1, 5, and 15). The spacing and length of this ejector were varied in the manner described above; however, no extension was made to the initial 70 in. length. 


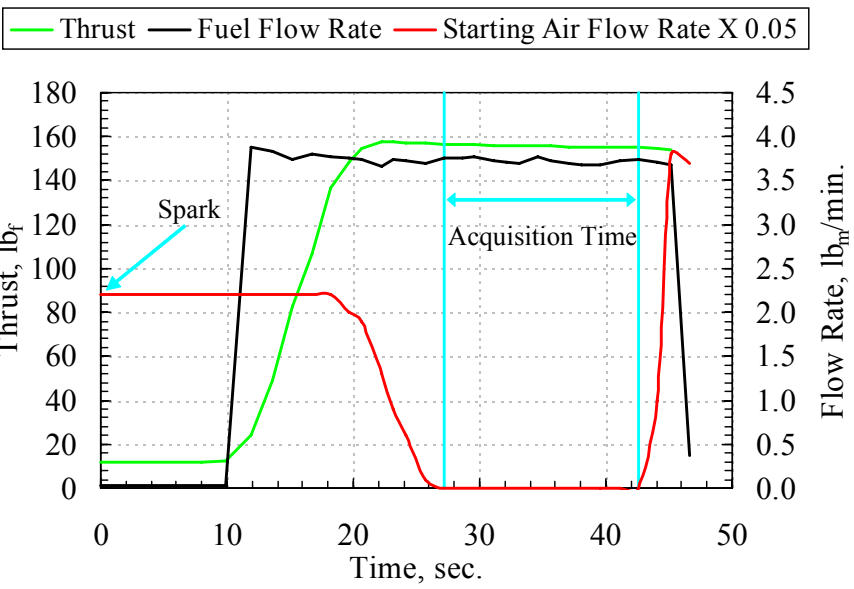

Figure 5.- -Measured thrust as a function of time for a typical pulsejet and ejector combination. Fuel and starting air flow rates are also shown.

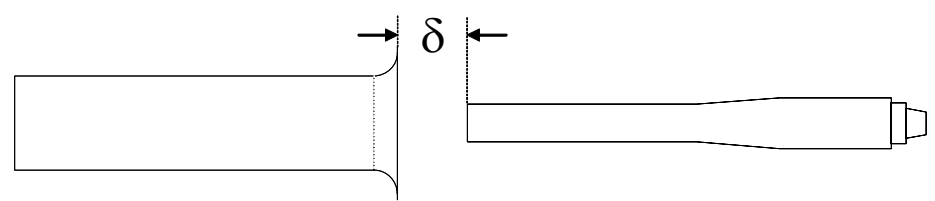

Figure 6.- Schematic of ejector spacing variation. The schematic is to scale.

\section{Results and Discussion}

\section{A. Straight, Cylindrical Ejectors}

1. Driver-to-ejector spacing variations.-Although spacing variation testing was performed on every ejector configuration, the results tended to be similar in trend. As such, results from only one configuration will be shown. Figure 7 displays the thrust augmentation as a function of driver-to-ejector spacing for the 16 in. diameter ejector, of 65 in. length. The spacing has been normalized by the driver diameter, $d$. Results are presented using both Methods I (baseline measured pulsejet thrust) and II (pulsejet thrust estimated from the fuel flow rate curve-fit of figure 3) to compute thrust augmentation. Also shown are the results from the small scale pulsejet experiment of reference 3 . Negative values of ejector spacing indicate that the exhaust plane of the pulsejet was actually inside the ejector. In the reference 3 experiment, such measurements were not possible as the pulsejet would cease to operate at low spacing values. The same phenomenon occurred in the present experiment, but at much smaller, even negative values. It is interesting to note that the augmentation reaches a peak as the ejector and driver are brought closer together. It then decreases to a minimum, and begins to rise again as the driver is brought into the ejector interior. It is not known whether a second peak exists because, as mentioned, the pulsejet stopped operating. Such 'twin peak' behavior was observed in the PDE driven experiment of reference 5. The spacing yielding peak performance is approximately 2.0 pulsejet diameters. This value is similar to, but slightly larger than, the value found in the small scale experiment. Comparison with other experimental results (refs. 4 and 5) indicates that the value varies between 1 and 2.5 driver diameters. It therefore appears to be a somewhat experiment specific parameter, perhaps depending on both the physical geometry of the driver and the characteristic of the unsteady pulse.

Optimal ejector spacing was found to be invariant with changing ejector length. However, it should be kept in mind that only one diameter ejector was varied in this manner. 


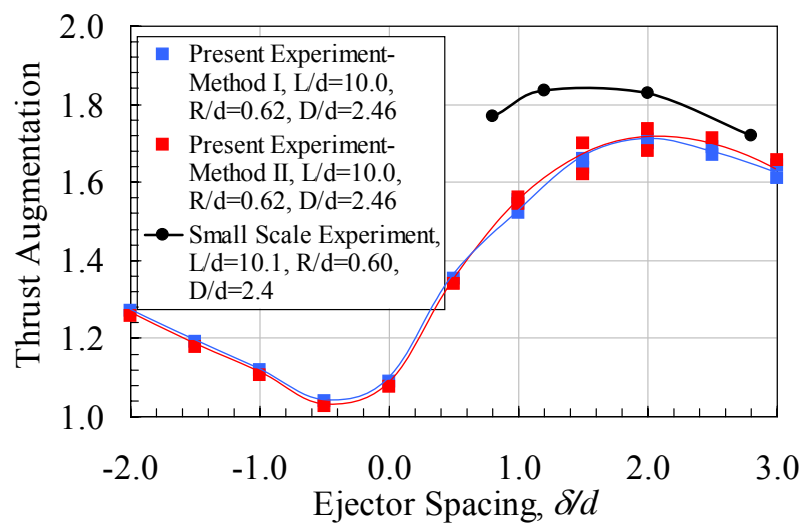

Figure 7.- Thrust augmentation as a function of driver-to-ejector spacing for the $D / d=2.46$, $L / d=10.0$ ejector.

For variations in diameter using a fixed length, the optimal spacing followed a nearly perfect linear relationship described by

$$
\left(\frac{\delta}{d}\right)_{\text {optimal }}=0.90\left(\frac{D}{d}\right)-0.27
$$

The general increase in optimal spacing as ejector diameter increases is consistent with the results of references 3 through 5 .

2. Ejector diameter variations. - Thrust augmentation levels obtained with optimally spaced, fixed length ejectors are shown as a function of ejector diameter in figure 8 . The ejector diameter has been normalized by the driver diameter. Once again, results using both Methods I and II to obtain pulsejet thrust are shown. For comparison, results from the reference 3 small scale pulsejet experiment also appear. There is a clear optimal ejector diameter, and for both the large and small scale experimental results it appears to be very nearly 2.5 driver diameters. This result is remarkably consistent over a range of drivers. Table 2 lists the ejector to driver diameter ratios at which peak augmentation levels were found in a number of experiments using cylindrical or nearly cylindrical ejectors. The values all fall between 2.4 and 3.0, indicating that the optimal ejector diameter is a near constant multiple of the driver diameter, probably having a weaker secondary dependence on other, as yet unknown parameters. This result supports the notion that the vortex emitted with each pulse of the driver plays a key role in unsteady thrust augmentation since, as was pointed out in references 5 and 6, its size (bounding diameter) appears to follow the same ratio when divided by the driver diameter.

It is noted that although the optimal value of $D / d$ is nearly the same for all of these ejectors, the thrust augmentation obtained is not. Part of the reason for this may be that while all of the unsteady drivers emit a vortex, the amount of vorticity present, its velocity, the balance between fluid trapped in the vortex and that which follows behind, and the interaction between vortex bound fluid and trailing jet fluid may be vastly different. These features may play a key role in the entrainment of and momentum transfer to the secondary fluid in the ejector; although the mechanism isn't clear (refs. 6 and 16).

It was suggested in reference 6 (and based on the observations of reference 17) that a characterizing feature of the emitted pulse, essentially a type of inverted Strouhal Number, may be a correlating parameter to the peak thrust augmentation achievable with an ejector that has been optimized for length and diameter. In that paper, the parameter, heretofore referred to as the non-dimensional formation time, was defined as

$$
\tau_{f}=\frac{\sqrt{\overline{u^{\prime 2}}}}{2 f d}
$$




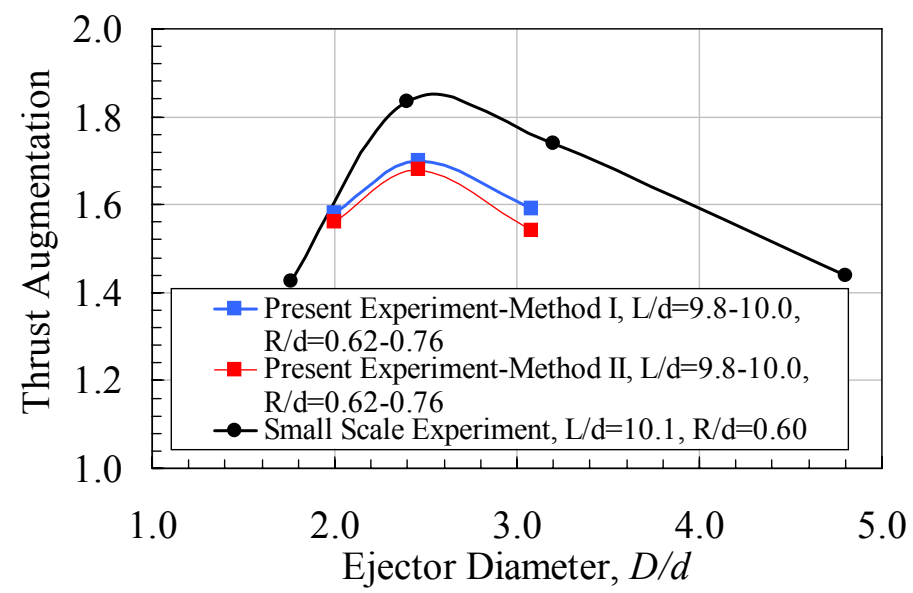

Figure 8.-Thrust augmentation as a function of ejector diameter for the $L / d=10.0$ ejectors. The ejectors are optimally spaced for each point. Data from the reference 3 small scale experiment is also shown.

TABLE 2.-OPTIMAL $D / d$ VALUES

\begin{tabular}{|c|l|c|c|c|}
\hline Reference & \multicolumn{1}{|c|}{ Driver type } & $\phi_{\max }$ & $\begin{array}{c}\text { Optimal } \\
D / d\end{array}$ & $\begin{array}{c}d \\
\text { (in.) }\end{array}$ \\
\hline Present & Large pulsejet & 1.71 & 2.4 & 6.50 \\
\hline 2 & Chopped pulse & 1.45 & 3.0 & 3.14 \\
\hline 3 & Small pulsejet & 1.83 & 2.5 & 1.25 \\
\hline 4 & Resonance tube & 1.38 & $2.7^{*}$ & 1.50 \\
\hline 5 & PDE & 2.00 & 3.0 & 1.00 \\
\hline 6 & Synthetic jet & 1.67 & $2.4^{+}$ & 0.93 \\
\hline 7 & PDE & 2.10 & 3.0 & 1.93 \\
\hline "Using the hydraulic diameter of the driver 275 Hz. driver. \\
'Using 'effective diameter' measured w/PIV. \\
\hline
\end{tabular}

where $f$ is the frequency of operation, and $\sqrt{\overline{u^{\prime 2}}}$ is the root mean square of the periodic velocity fluctuations in the exit plane of the driver. This velocity can be estimate from measured thrust, mean flow rate and temperature of the driving jet. It was argued that peak thrust augmentation should rise with formation time up to some critical value, $\tau_{f}^{\text {crit }}$. Beyond this value, peak thrust augmentation should slowly fall. Figure 9 shows the peak thrust augmentation obtained as a function of formation time for the present experiment and several others for which sufficient data was available ${ }^{*}$. A simple parabolic fit through the data is also shown. The data seems to follow the expected trend, indicating a value of $\tau_{f}^{\text {crit }}$ near 40 ; however, the data is admittedly sparse and much more is needed. Furthermore, it was noted in reference 6 that other experimental results don't fall on this same curve. This implies that other factors such as the exhaust gas temperature (relative to the entrained secondary flow) may play a significant role in determining peak thrust augmentation. The experiments represented in figure 9 have vastly different exhaust temperatures for which no accounting has been made other than the effect on $\sqrt{\overline{{u^{\prime 2}}^{2}}}$. Beyond this, the use of formation time as is done here provides no insight into the physical mechanism of unsteady thrust augmentation. It only provides a potentially predictive correlating parameter, albeit one that is fairly compelling.

${ }^{*}$ For the reference 5 PDE experiment the rms velocity was obtained from a numerical simulation matching flow rate and thrust. Because the thrust producing period of a typical PDE is only a small fraction of the operating period, only the thrust producing period was used in the rms velocity calculation. The inverse of this period was used for $f$ in equation (3). 


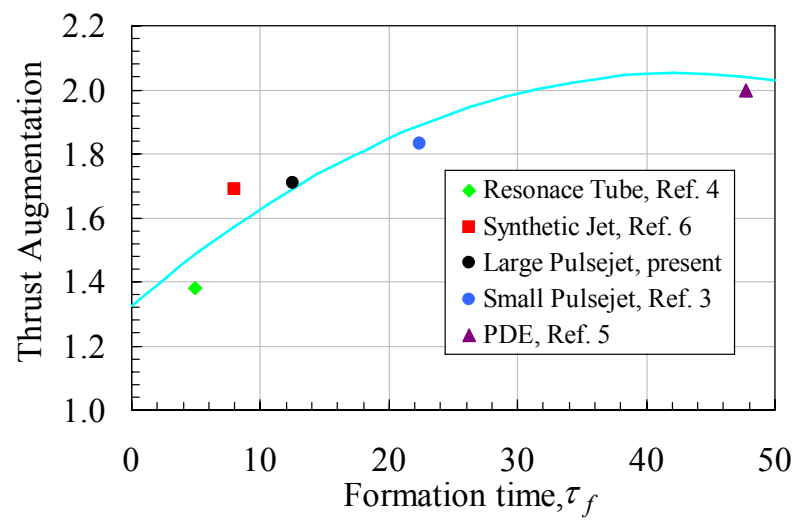

Figure 9.- Peak thrust augmentation as a function of formation time for the present, and several other experiments.

3. Ejector length variation.-As stated earlier, length variation tests were only performed on a single cylindrical ejector. The 16 in. diameter ejector was chosen $(D / d=2.46)$ since it had yielded the highest performance at the as-built $65 \mathrm{in}$. length. The variation in thrust augmentation as a function of ejector length is shown in figure 10 . The length has been normalized by the driver diameter. Results from the small pulsejet experiment of reference 3 are also shown. The trends of the two experiments are somewhat different; however, it is noted that the peak value of thrust augmentation occurs at the same value of $L / d=10$ for both. This turned out to be the as-built length in the present experiment.

This ratio does not hold for the other unsteady experiments; however, it is not clear that it should. There are several conceptual models for the mechanism by which fluid is entrained and energized in the ejector. One posits a sort of piston-like behavior of the driver flow which delivers momentum to the secondary flow via direct pressure exchange as the two flows collide within the ejector. A second notion suggests that the mechanism of entrainment and momentum exchange is the same as that for a steady ejector, namely shear flow and mixing (most likely driven by turbulence). Secondary fluid is literally dragged into the ejector and accelerated. In this concept, the emitted vortex serves the function of vastly increasing the shearing surface area (compared to a steady jet) due both to its initial structure and to its observed disintegration ${ }^{\dagger}$.

If the latter mechanism is correct, it might be expected that the emitted vortex would decelerate (even as it broke apart) at a rate proportional to its surface area and to the square of the difference between its velocity and that of the secondary flow. That is

$$
U_{v} \frac{d U_{v}}{d x} \approx-\alpha\left(\frac{\rho_{s}}{\rho_{v}}\right)\left(\frac{S}{V}\right)\left(U_{v}-U_{s}\right)^{2}
$$

where $\rho_{v}$ is the density of the vortex, $V$ is the vortex volume, $S$ is the surface area, $U_{v}$ is the velocity of the vortex, $U_{s}$ is the average velocity of the secondary flow (assumed constant), $\alpha$ is a constant, and $\rho_{s}$ is the density of the secondary flow. Assuming that the vortex volume and surface area are proportional to the cube and square of its diameter respectively, and assuming further that its diameter is proportional to the diameter of the driver, the ratio $(S / V)$ in equation (4) simply becomes proportional to $(1 / d)$, i.e.,

$$
U_{v} \frac{d\left(U_{v}-U_{s}\right)}{d(x / d)} \approx-\kappa\left(\frac{\rho_{s}}{\rho_{v}}\right)\left(U_{v}-U_{s}\right)^{2}
$$

With $\kappa$ a constant, equation (5) can be solved numerically to yield $x / d$ as a function of $\left(U_{v}-U_{s}\right)$, for any given $\rho_{s} / \rho_{v}$ and $U_{v}^{\text {initial }} / U_{s}$, which is the initial vortex velocity as it enters the ejector divided by the average secondary

\footnotetext{
'Observations of vorticity in the ejector exit region of the references 11 and 12 indicate no coherent vortical flow structure at radial distances less than the ejector diameter.
} 


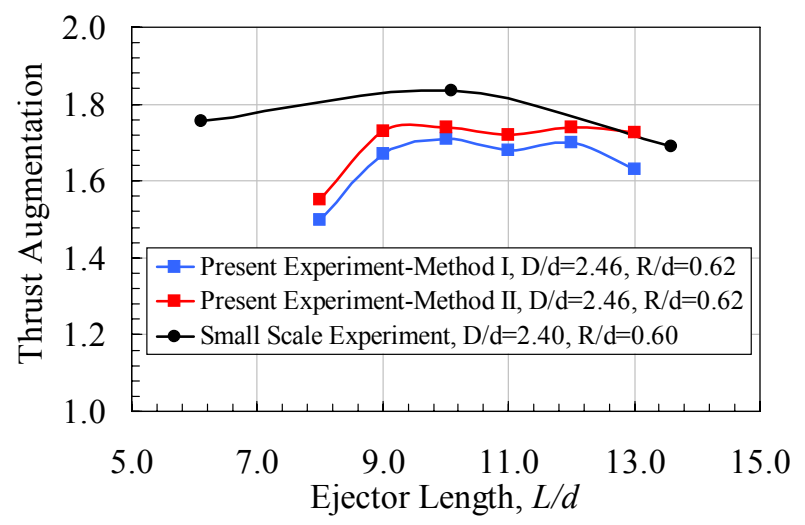

Figure 10.-Thrust augmentation as a function of ejector length for the $D / d=2.46$ ejector. The ejectors are optimally spaced for each point. Data from the reference 3 small scale experiment is also shown.

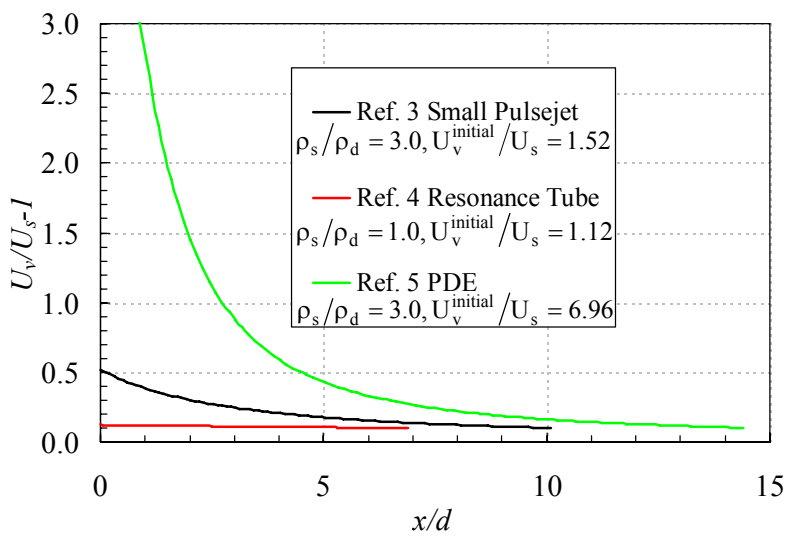

Figure 11.-Numerical solution to equation (5) for several relevant parameters of density ratio and vortex velocity ratio. The value of $\kappa$ in equation (5) is 0.32 .

flow velocity. If the optimal ejector length, $L_{\text {opt }}$ is defined as that value of $x$ for which $\left(U_{v} / U_{s}-1\right)$ is less than some specified small value such as 0.1 , and if estimates of $U_{v}^{\text {initial }} / U_{s}$ and $\rho_{s} / \rho_{v}$ are available, then equation (5) can be used to obtain $L_{\text {opt }} / d$. This is illustrated in figure 11 which shows the numerical solution to equation (5) for different values of the parameters $U_{v}^{\text {initial }} / U_{s}$ and $\rho_{s} / \rho_{v}$.

Estimates for $U_{v}^{\text {initial }}$ and $U_{s}$ were obtained for the references. 3, 4, and 5 experiments using PIV data from references 11,16 , and $12^{\ddagger}$. They are listed in table 3 . Values of $\rho_{s} / \rho_{v}$ were not available. For the reference 4 resonance tube, this ratio should be near 1.0 since the driver gas was at near ambient temperature. For the references 3 and 5 pulsejet and PDE driven experiments, the ratio was estimated at approximately 3.0. This estimate assumes that the very hot, low density gas from each driver entrains a certain amount of cooler air as it forms the emitted vortex.

TABLE 3.-VORTEX AND SECONDARY FLOW VELOCITIES, AND OPTIMAL $L / D$ VALUES.

\begin{tabular}{|c|c|c|c|c|c|}
\hline Reference & Driver type & $\begin{array}{c}\mathrm{U}_{\mathrm{v}} \\
(\mathrm{ft} / \mathrm{s})\end{array}$ & $\begin{array}{c}\mathrm{U}_{\mathrm{s}} \\
(\mathrm{ft} / \mathrm{s})\end{array}$ & $\frac{\rho_{s}}{\rho_{v}}$ & $\mathrm{~L}_{\text {opt }} / \mathrm{d}$ \\
\hline 3 & Small Pulsejet & 460 & 303 & 3.0 & 10.1 \\
\hline 4 & Resonance Tube & 275 & 245 & 1.0 & 6.5 \\
\hline 5 & PDE & 800 & 115 & 3.0 & 14.6 \\
\hline
\end{tabular}

${ }^{\sharp}$ For the reference 4 experiment, $U_{s}$ was obtained from hotwire measurements taken in the exit plane of the ejector. 
When these values of $U_{v}^{\text {initial }}, U_{s}$, and $\rho_{s} / \rho_{v}$ were used in the numerical solution of equation (5), together with an ending criterion $\left(U_{V} / U_{s}-1\right)=0.1$, it was found that for a single value of $\kappa=0.32$, the values for $L_{o p t} / d$ calculated were almost exactly the values found experimentally, and listed in table 3 . This result is by no means proof of the shear mechanism for ejector entrainment and thrust augmentation, particularly given the scarcity of data and the density estimates used. It is nevertheless suggestive that this mechanism predominates.

Note that equation (5) may be rewritten as an ordinary differential equation in time as

$$
\frac{d\left(U_{v}-U_{s}\right)}{d t} \approx-\frac{\kappa}{d}\left(\frac{\rho_{s}}{\rho_{v}}\right)\left(U_{v}-U_{s}\right)^{2}
$$

Integrating this equation using the parameters listed above presumably gives the time required for the emitted vortex to travel down the ejector, decelerate, degenerate, and accelerate the secondary fluid. The inverse of this time provides an estimate for the optimal operational frequency from the perspective of shear-driven momentum transfer. For the references 3,4 , and 5 experiments, these frequencies are listed in table 4 , along with the actual operational frequencies of the devices. All other things being equal, it would be intuitively expected that the closer together the optimal and operational frequencies, the higher the thrust augmentation. If this is true, it suggests that PDE's which for a given length ideally operate at a much higher frequency than that listed in table 3 , could obtain even higher augmentations levels than have been reported to date. It would also suggest that the present experiment, while generally exhibiting lower overall thrust augmentation values compared to those of the small scale pulsejet experiment of reference 3 , is actually better matched in terms of this optimal frequency criterion. The reason for this is as follows. The value of $L_{\text {opt }} / d$ found in the present experiment is identical to that of reference 3 . It is expected that the values of $\rho_{s} / \rho_{v}, U_{v}^{\text {initial }}, U_{s}$ are therefore quite similar. These can be used to integrate equation (6) but with the larger diameter of the present experiment. The resulting optimal frequency is found to be $67 \mathrm{~Hz}$, which is very close, and therefore better matched, to the actual operating frequency of $69 \mathrm{~Hz}$.

TABLE 4.- OPTIMAL EJECTOR AND ACTUAL DRIVER OPERATIONAL FREQUENCIES

\begin{tabular}{|c|c|c|c|}
\hline Reference & Driver type & $\begin{array}{c}f_{\text {opt }} \\
(\mathrm{Hz})\end{array}$ & $\begin{array}{c}f_{\text {driver }} \\
(\mathrm{Hz})\end{array}$ \\
\hline 3 & Small pulsejet & 350 & 220 \\
\hline 4 & Resonance tube & 335 & 275 \\
\hline 5 & PDE & 135 & 20 \\
\hline
\end{tabular}

\section{B. Tapered, Conical Ejector}

As mentioned earlier, only one diameter of tapered, conical ejector was tested. The length was varied using the same technique as that for the cylindrical ejector. Similarly, at each length the driver-to-ejector spacing was varied until the highest augmentation was achieved. As with the straight ejectors, this optimal spacing was very nearly 2 driver diameters for every length. The results of the length variation tests are shown in figure 12, along with those from the small scale pulsejet experiment of reference 3. Like the small scale experiment, the maximum augmentation achieved was higher with the tapered ejector than with the best of the straight type. Both experiments also show much more sensitivity at the shorter lengths than was seen with the straight ejectors. However, the small scale experiment has a clear length at which peak augmentation is observed, whereas the present experiment exhibits nearly flat region where the augmentation is high and insensitive to length. The start of this region and the peak performance point of the small experiment both appear to occur between $8<L_{\text {opt }} / d<8$.5. The peak augmentation obtained in the present experiment was 1.83, while the small scale experiment yielded a value of 1.98 . The same trend was seen with the straight ejectors. As mentioned earlier, part of the reason for this may be due to the somewhat different vortex parameters associated with the two drivers (despite their both being valved pulsejets).

Some of the difference may also be attributed to the slightly different nature of the ejectors used in the two experiments; however, these are fairly subtle. Figure 13 shows a profile of the best performing straight and tapered ejectors used in the reference 3 work. The straight ejector is seen to actually have a short diffusing section at the exhaust end, and both have a half circle inlet profile as opposed to the quarter round profile of the present work. 


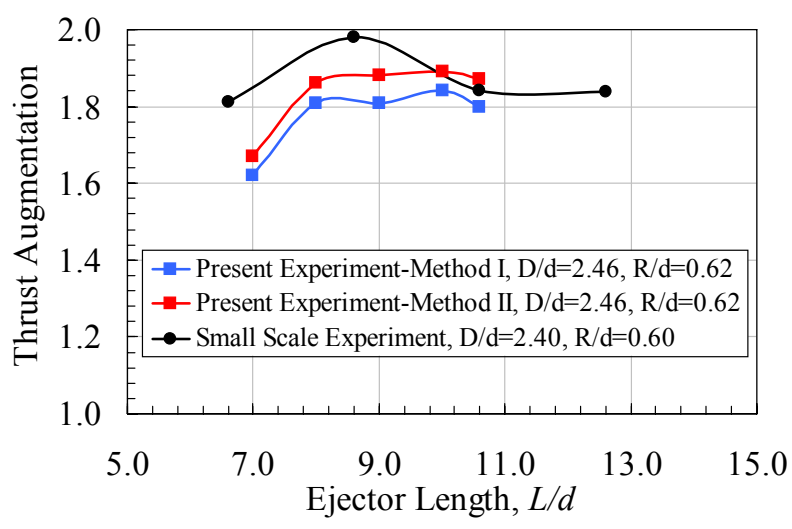

Figure 12.-Thrust augmentation as a function of ejector length for the $D / d=2.46$ tapered ejectors. The ejectors are optimally spaced for each point. Data from the reference 3 small scale experiment is also shown.

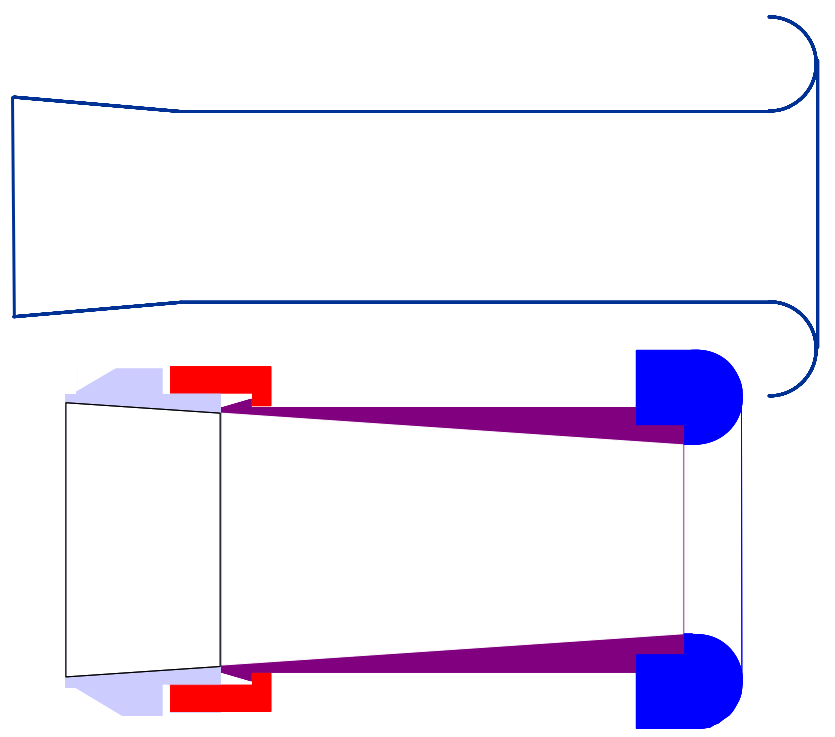

Figure 13.- Straight and tapered ejector profiles used in the small scale pulsejet experiment of reference 3.

Another possible explanation for the comparatively lower peak augmentation in the large system may lie in the scale of the turbulence which is involved in the exchange of momentum between the driver and the secondary flow. There are numerous potential turbulence length scales in a pulsejet. Some are governed by the physical size of the unit, but others are not. It is possible that the scales from say, combustion, and the exhaust plane shear layer coincide in the small unit and thus, being encased in the emitted vortex, efficiently transfer the large scale vortex rotational energy to the secondary flow. In the large unit, this matching of scales may not hold. Of course, there is no proof yet for this (rather intuitive) explanation other than the observation that the measured turbulence levels in the emitted vortex of several unsteady thrust experiments are quite high (refs. 6, 11, and 12). Clearly, much more investigation is needed into the issue of peak thrust augmentation in unsteady thrust systems in general, and in large versus small systems in particular. 


\section{Conclusion}

A large scale pulsejet-driven ejector system was tested with the objective of obtaining ejector dimensions which maximize thrust augmentation. Tests were conducted using ejectors of various length, diameter, and cross sectional profile. The spacing between the pulsejet exit and ejector inlet was also examined for its influence on performance. Comparisons with other unsteady ejector experiments were also made both in the level of augmentation achieved and in the dimensions of the optimized ejectors. A peak thrust augmentation value of 1.71 was obtained with straight ejectors. The optimized ejector diameter was found to be 2.46 times the pulsejet driver diameter of $6.5 \mathrm{in}$. This ratio was observed to be nearly constant over numerous experiments and may therefore be a sizing rule. The optimal length was found to be 10 times the driver diameter. This result was found to be the same as another, small scale pulsejet experiment, but somewhat different from those where another driving source was used. It was found that the tapered profile ejector yielded a higher thrust augmentation than the best of the straight profile series. The value obtained was 1.81. This result was consistent with numerous other unsteady thrust augmentation experiments. Additional research is needed to determine if there is an optimal ejector taper angle, and if that angle can be related to parameters of the driver.

\section{References}

1. Lockwood, R.M. "Interim Summary Report on Investigation of the Process of Energy Transfer from an Intermittent Jet to Secondary Fluid in an Ejector-Type Thrust Augmenter," Hiller Aircraft Report No. ARD286, March, 1961.

2. Binder, G. and Didelle, H, "Improvement of Ejector Thrust Augmentation by pulsating or flapping Jets," Paper E3 of Proc. 2nd Symposium on Jet Pumps \& Ejectors and Gas Lift Techniques, Cambridge, England, March 1975.

3. Paxson, D.E., Wilson, J., and Dougherty, K.T., "Unsteady Ejector Performance: An Experimental Investigation Using a Pulsejet Driver," AIAA paper 2002-3915, July, 2002.

4. Wilson, J., and Paxson, D.E., "Unsteady Ejector Performance: An Experimental Investigation Using a Resonance Tube Driver," AIAA paper 2002-3632, July, 2002.

5. Wilson, J., Sgondea, A., Paxson, D.E., Rosenthal, R., "Parametric Investigation of Thrust Augmentation by Ejectors on a Pulsed Detonation Tube," AIAA paper 2005-4208, July, 2005.

6. Paxson, D.E. Wernet, M.P., John, W.T., "An Experimental Investigation of Unsteady Thrust Augmentation Using a Speaker-Driven Jet," AIAA-2004-0092, January, 2004.

7. Landry, K., Shehadeh, R., Bouvet, N., Lee, S.-Y, Pal, S., and Santoro, R.J., "Effect of Operating Frequency on PDE Driven Ejector Thrust Performance," AIAA paper 2005-3832, July, 2005.

8. Choutapalli, I.M., Alkislar, M.B., Krothapalli, A. Lourenco, L.M., "An Experimental Study of Pulsed Jet Ejector," AIAA paper 2005-1208, January, 2005.

9. Allgood, D. Gutmark, E. Hoke, J. Bradley, R., Schauer, F., "Performance Measurements of Pulse Detonation Engine Ejectors," AIAA paper 2005-223, January, 2005.

10. Wilson, J. "Effect of Pulse Length and Ejector Radius on Unsteady Ejector Performance," AIAA paper 20053829, July, 2005.

11. John, W.T., Paxson, D.E., Wernet, M.P., "Conditionally Sampled Pulsejet Driven Ejector Flow Field Using DPIV," AIAA paper 2002-3231, June, 2002.

12. Opalski, A.B., Paxson, D.E., Wernet, M.P., "Detonation Driven Ejector Exhaust Flow Characterization Using Planar DPIV," AIAA paper 2005-4379, July, 2005.

13. Litke, P.J., Schauer, F.R., Paxson, D.E., Bradley, R.P., Hoke, J.L., "Assessment of the Performance of a Pulsejet and Comparison with a Pulsed-Detonation Engine," AIAA paper 2005-0228, January, 2005.

14. Schauer, F.R., Stutrud, J., and Bradley, R.P., "Detonation Initiation Studies and Performance Results for Pulsed Detonation Engine Applications," AIAA Paper 2001-1129, January 2001.

15. Paxson, D.E., "2003 Pulse Detonation Engine Project: University/Government Spring Ejector Meeting," unpublished presentation, 2003.

16. Wilson, J. "Vortex Rings Generated by a Shrouded Hartmann-Sprenger Tube," AIAA paper 2005-5163, June 2005.

17. Gharib, M., Rambod, E., Shariff, K., "A universal time scale for vortex ring formation," Journal of Fluid Mechanics, vol. 360, pp. 121-140, 1998. 
Public reporting burden for this collection of information is estimated to average 1 hour per response, including the time for reviewing instructions, searching existing data sources, gathering and maintaining the data needed, and completing and reviewing the collection of information. Send comments regarding this burden estimate or any other aspect of this collection of information, including suggestions for reducing this burden, to Washington Headquarters Services, Directorate for Information Operations and Reports, 1215 Jefferson Davis Highway, Suite 1204, Arlington, VA 22202-4302, and to the Office of Management and Budget, Paperwork Reduction Project (0704-0188), Washington, DC 20503.

\begin{tabular}{|l|l|l}
\hline 1. AGENCY USE ONLY (Leave blank) & $\begin{array}{c}\text { 2. REPORT DATE } \\
\text { May } 2006\end{array}$ & $\begin{array}{r}\text { 3. REPORT TYPE AND DATES COVERED } \\
\text { Technical Memorandum }\end{array}$ \\
\hline
\end{tabular}

\section{TITLE AND SUBTITLE}

Performance Assessment of a Large Scale Pulsejet-Driven Ejector System

\section{FUNDING NUMBERS}

WBS 599489.02.07.03

\section{AUTHOR(S)}

Daniel E. Paxson, Paul J. Litke, Frederick R. Schauer, Royce P. Bradley, and John L. Hoke

\section{PERFORMING ORGANIZATION NAME(S) AND ADDRESS(ES)}

National Aeronautics and Space Administration

John H. Glenn Research Center at Lewis Field

Cleveland, Ohio 44135-3191
8. PERFORMING ORGANIZATION REPORT NUMBER

E-15472

\section{SPONSORING/MONITORING AGENCY NAME(S) AND ADDRESS(ES)}

National Aeronautics and Space Administration

Washington, DC 20546-0001
10. SPONSORING/MONITORING AGENCY REPORT NUMBER

NASA TM-2006-214224

AIAA-2006-1021

\section{SUPPLEMENTARY NOTES}

Prepared for the 44th Aerospace Sciences Meeting and Exhibit sponsored by the American Institute of Aeronautics and Astronautics, Reno, Nevada, January 9-12, 2006. Daniel E. Paxson, NASA Glenn Research Center; Paul J. Litke and Frederick R.Schauer, Air Force Research Laboratory, Wright-Patterson Air Force Base, Dayton, Ohio 45433;

Royce P. Bradley and John L. Hoke, Innovative Scientific Solutions, Inc., Dayton, Ohio 45440. Responsible person, Daniel E. Paxson, organization code RIC, 216-433-8334.

12a. DISTRIBUTION/AVAILABILITY STATEMENT 12b. DISTRIBUTION CODE

Unclassified - Unlimited

Subject Category: 07

Available electronically at http://gltrs.grc.nasa.gov

This publication is available from the NASA Center for AeroSpace Information, 301-621-0390.

13. ABSTRACT (Maximum 200 words)

Unsteady thrust augmentation was measured on a large scale driver/ejector system. A $72 \mathrm{in}$. long, $6.5 \mathrm{in}$. diameter, $100 \mathrm{lb}$ pulsejet was tested with a series of straight, cylindrical ejectors of varying length, and diameter. A tapered ejector configuration of varying length was also tested. The objectives of the testing were to determine the dimensions of the ejectors which maximize thrust augmentation, and to compare the dimensions and augmentation levels so obtained with those of other, similarly maximized, but smaller scale systems on which much of the recent unsteady ejector thrust augmentation studies have been performed. An augmentation level of 1.71 was achieved with the cylindrical ejector configuration and 1.81 with the tapered ejector configuration. These levels are consistent with, but slightly lower than the highest levels achieved with the smaller systems. The ejector diameter yielding maximum augmentation was 2.46 times the diameter of the pulsejet. This ratio closely matches those of the small scale experiments. For the straight ejector, the length yielding maximum augmentation was 10 times the diameter of the pulsejet. This was also nearly the same as the small scale experiments. Testing procedures are described, as are the parametric variations in ejector geometry. Results are discussed in terms of their implications for general scaling of pulsed thrust ejector systems.

\section{SUBJECT TERMS}

Pulse detonation engines; Combustion; Thermodynamic cycles
15. NUMBER OF PAGES

19

16. PRICE CODE

\begin{tabular}{|c|c|c|}
\hline $\begin{array}{c}\text { 17. SECURITY CLASSIFICATION } \\
\text { OF REPORT } \\
\text { Unclassified }\end{array}$ & $\begin{array}{c}\text { 18. SECURITY CLASSIFICATION } \\
\text { OF THIS PAGE } \\
\text { Unclassified }\end{array}$ & $\begin{array}{c}\text { 19. SECURITY CLASSIFICATION } \\
\text { OF ABSTRACT } \\
\text { Unclassified }\end{array}$ \\
\hline
\end{tabular}

NSN 7540-01-280-5500
Standard Form 298 (Rev. 2-89)

Prescribed by ANSI Std. Z39-18 298-102 

